\title{
Belém de Dalcídio ou \\ História e Experiência Literária da Paisagem Urbana da Amazônia
}

\author{
Gunter Karl PRESSLER ${ }^{\mathrm{i}}$
}

\begin{abstract}
Resumo: Ao contrário de muitos livros sobre Amazônia que insistem no mito e na selva, até hoje, o nosso artigo aborda a questão da cultura e da literatura na Amazônia a partir do ponto histórico-geográfico e a conditio sine qua non de qualquer expressão cultural no sentido moderno, i.e., a partir da existência da cidade com vida pública e a política divulgada em jornais, revistas e livros, pressupondo imprensa, tipografias, círculos literários e mídias modernas. O primeiro jornal na Amazônia apareceu já em 1822 que tinha como redator-chefe Felipe Patroni, o segundo que circulou entre 1824 e 1827 , dirigido por Dom Romualdo de Seixas. Com a abertura da navegação livre do Rio Amazonas, em 1867, chegaram viajantes naturalistas à Amazônia, e com eles uma atenção maior à uma vida publica e de informações nacionais e internacionais e, no último quartel do século 19, desenvolveram-se intensas atividades jornalísticas e culturais com redatores e colaboradores. Deve ser observado que a cidade tinha no século 19 em sua maioria habitantes nativos e escravos e uma forte vivência de cultura popular. Como se modificou Belém e o interior do Pará, no final do século 19, com a extração intensiva da borracha na Amazônia? O nosso estudo apresenta enfoques de percepção e de vivência urbana não pelos padres, arquitetos ou viajantes, mas pelo romancista moderno, Dalcídio Jurandir (1909-1979), a fim de contribuir sobre a questão da fronteira entre cidade e campo e da vivência urbana e regional no ambiente dominado pela água e a floresta.
\end{abstract}

Palavras chave: Belém, Dalcídio Jurandir, paisagem, cidade.

\section{Belem from Dalcídio or History and Literary Experience of the Amazon urban place}

\begin{abstract}
Unlike many books on Amazon that insist on the myth and in the jungle, until today, our article addresses the issue of culture and literature in the Amazon from the historical-geographical perspective and the sine qua non condition of any cultural expression in modern sense, i.e., departing from the existence of the city with public life and politics published in newspapers, magazines and books, presupposing press, printings, literary circles and modern media. The first newspaper in the Amazon appeared already in 1822 had as editor in chief Felipe Patroni, the second one that circulated between 1824 and 1827, was directed by Don Romualdo de Seixas. With the opening of the free navigation of the Amazon River in 1867, naturalist travellers arrived to the Amazon, and with them greater attention to a public life and national and international information, in the last quarter of the 19th century, intense cultural and journalistic activities developed with editors and contributors. It should be noticed that the city in the 19th century had as inhabitants mostly native and slaves and a strong experience of popular culture. How did Belem and the interior of Para state change in the late 19th century, with the intensive extraction of rubber in the Amazon? Our study presents approaches of perception and urban living not by priests, architects or travelers, but by the modern novelist, Dalcídio Jurandir (1909-1979), in order to contribute on the issue of border between city and countryside and urban and regional experience in the environment dominated by water and forest.
\end{abstract}

Keywords: Belém, Dalcídio Jurandir, landscape, city.

Refletir e abordar a questão da cultura e da literatura na Amazônia significa - diante da sempre referida exuberância da natureza - ressaltar o ponto histórico-geográfico e a conditio sine qua non de qualquer expressão cultural no sentido moderno: a existência da cidade com vida pública e a política divulgada em jornais, revistas e livros, pressupondo imprensa, tipografias, círculos literários e mídias modernas $^{2}$. De uma vida pública, neste sentido, só pode-se falar na segunda metade do século 19. Anteriormente, consta-se, como ressalta Nelson Schapochnik, uma "ausência de fronteiras nítidas entre a esfera pública e a esfera privada" (SCHAPOCHNIK, 2000, p. 290).

Até o último quartel do século 19, Amazônia era uma região sem urbanização significativa (Belém tinha, em 1872, 62.000 habitantes e, em 1900, 96.560; Manaus era, em 1872, ainda um 
vilarejo de 29.330 habitantes e, em 1900, de 50.300; fontes IBGE). Do início de núcleos costeiros (São Luís e Belém), estendeu-se a habitação e a exploração econômica do interior (drogas do sertão) pelo projeto missionário, particularmente dos jesuítas, com a criação de aldeias-vilarejo nos séculos 17 e 18 (do delta do Rio Amazonas até ao Rio Negro e Rio Solimões; a distância fluvial BelémManaus: 1606 km; Manaus-Tabatinga, na fronteira com Peru mais $1622 \mathrm{~km}$ ). O projeto políticomilitar pombalino implantou não só uma fortificação da região amazônica, mas também projetos urbanos, pensando, p.e., nas realizações do arquiteto Antônio Landi em Belém (o Barroco Amazônico, a igreja de Santo Alexandre). Ressalta-se a importância da esfera pública burguesa, da cultura escrita presente nas bibliotecas e na imprensa no século 19 e 20 para a vida moderna com produções culturais em mídias diferentes. O ciclo de borracha, no final do século 19, trouxe mais uma onda de modernização urbana para Amazônia, não só em Belém e Manaus, mas também no interior, Gurupá com sua antiga fortificação, e na ilha de Marajó.

A construção de boulevards, de bondes elétricos e de iluminações elétricas possibilitou uma vida pública diferente, a visita de cafés e teatros e, posteriormente, de cinemas, impulsionou uma vida cultural que não seria possível sem uma produção gráfica e uma tipografia ${ }^{3}$. Podemos dizer, sem uma imprensa, sem uma livraria ${ }^{4}$, sem círculos de apresentação e de divulgação, a criação artística e, especificamente, a criação literária não pode nascer ou depender da oralidade (a cultura popular que não precisa da escrita ${ }^{5}$, somente o registro dessa cultura; mas com o registro perde gradativamente sua função social e cultural-viva, torna-se folclore — ato de rememoração de origens ${ }^{6}$ ). A Formação da Literatura Brasileira, de Antônio Candido, aborda a questão historiográfica de forma sistemática e construtiva, mas o Norte do Brasil ficou fora de reflexão destas pesquisas, ou melhor, Amazônia continua ser vista sob o enfoque do mito e como "terra misteriosa":

A Amazônia não tem constituído simplesmente uma atração turística e hoje sobretudo
econômica, mas também uma atração literária. O espírito de aventura sempre foi seduzido
pelos seus segredos e mistérios e esse espírito também existe na literatura.
Existe mesmo uma Amazônia de nossos sonhos, uma Amazônia fabulosa, a das mulheres
guerreiras e a das pedras verdes, dos pássaros vampiros e dos peixes fálicos, como também
existe uma Amazônia real, talvez mais maravilhosa que a da lenda, como a das tribos ainda
sem contato com o que chamamos de civilização, verdadeiro fenômeno dos dias presentes [...]
Para a ficção literária ela constituía e ainda constitui amplo foco de interesse. Muitos foram os
escritores que, aborígenes ou estranhos, se ocuparam desse paraíso, ou seja, desse inferno
verde e aquático, aplicando-lhe um tratamento de que era reflexo esse epíteto de 'inferno', mas
um inferno cheio de seduções, como, alias, à puridade, não deixava de interessar tudo que
tomasse o cheiro de pecado" (LINHARES, 1987: 371)

Mesmo assim, ao contrário de muitos livros sobre Amazônia que insistem no mito e na selva, até hoje; o primeiro jornal na Amazônia apareceu em 1822 que tinha como redator-chefe Felipe Patroni, o segundo que circulou entre 1824 e 1827, dirigido por Dom Romualdo de Seixas e, depois muitos outros jornais de notícia e literário sugiram. Amazônia passou pela grande revolta da “Cabanagem” (1834-40) que marcou a relação da região Norte com o novo Estado do Brasil. Com a 
abertura da navegação livre do Rio Amazonas, em 1867, chegaram viajantes naturalistas à Amazônia. Desta forma, o

Pará, pela sua posição geográfica, pelo clima e pelo permanente intercâmbio com a Europa, sofreu muito dessa influência quanto aos habitantes, a língua e o modo de viver do outro lado do Atlântico. Para os paraenses de outros tempos era bem mais fácil ir à Europa do que ao sul do país [...] As manifestações literárias envolvendo questões sociais e políticas, faziam germinar os ideais separatistas, a análise fria da situação imposta aos índios, a posição vexatória da escravatura, além dos sentimentos republicanos.

(MEIRA/ILDONE/CASTRO, 1990: 19 e 61)

De outro lado, a cidade tinha ainda em sua maioria habitantes nativos e escravos e uma forte vivência de cultura popular ${ }^{7}$. No último quartel do século 19, desenvolveram-se intensas atividades jornalísticas e culturais com redatores e colaboradores o que "havia de melhor na elite cultural da terra, nomes que chegaram a alcançar grande projeção na vida política, científica e nas letras do Pará e do Brasil, na primeira metade do século XX"8. Também no interior dos Estados da Amazônia, foi importante a evolução da imprensa: Muaná e Cachoeira do Arari, na Ilha do Marajó; em Santarém, na entrada do Tapajós no Rio Amazonas, “aparecem e desaparecem [...] mais de vinte jornais, geralmente de fundo político" (MEIRA/ILDONE/CASTRO, 1990: 74). A política do governo imperial seguindo a política de Portugal pombalina, implantou a escolarização como projeto de Estado, depois da expulsão dos Jesuítas; por exemplo, em 1841, “funcionava em Belém um Liceu e mais tarde, em 1871, abria-se uma Escola Normal [em Manaus] o Liceu só chegou em 1869 e a Escola Normal em 1881 [...] O ensino superior, este só na República teve ocasião de surgir. Primeiro, uma Faculdade Livre, de Direito, em Belém. Farias Brito foi professor nela, de Filosofia de Direito. Depois, outra, em Manaus". O Positivismo impulsionou mais ainda as atividades científicas ("Museu de História Natural", posteriormente, o "Museu Goeldi", 1871/1894) e de ensino com a chegada de Carlos Gomes, as atividades culturais.

O historiador e crítico cultural, José Veríssimo, foi importante na sua vivência em Belém, fundou "além da Revista Amazônica, uma Sociedade Promotora da Instrução, organizou o Clube Republicano ao lado de Lauro Sodré e participou, em Paris, de um Congresso de Antropologia [...] abriu o Colégio Americano, com a inovação do jardim de infância. Depois emigrou para o Rio e nunca mais voltou a Belém"10 e, pode-se constatar, esqueceu a literatura da Amazônia na sua História da Literatura Brasileira, de 1916. Nem o co-fundador e também paraense, Herculano Inglês de Sousa, entrou na historiografia brasileira. Hoje considerado o fundador do Naturalismo Brasileira, ao lado de Aluísio Azevedo, publicou três romances entre 1870 e 1876.

Somente em 1922, José Eustachio de Azevedo levantou a bandeira da literatura paraense (pode ser num vulto de certa "nacionalidade regional") e critica, particularmente, seu conterrâneo e historiador da literatura, José Veríssimo que "esquecendo-se sempre dos intelectuais paraenses"11. Mas constata autocraticamente e na ideologia do seu tempo que o 
Pará [...] levou muito tempo cuidando do desbravamento de seu sólo, em luta constante com o aborigene desconfiado e rebelde. E se o seu estacionamento e decadência eram devidos ao arrocho de governos antagônicos e à rude aspereza do clima equatorial, contribuíam poderosamente para o seu retardamento etnológico, a influência de fatores vários de imigração, a convivência e a união com o índio, o português tarado e o negro imbecil [...] em troca do ouro e dos produtos naturais, como o anil, o cacáu, a salsa, o arroz, a baunilha, etc. que recebiam a grosso, só nos enviavam a barregan, o criminoso e o africano.

(J.E. de Azevedo, 1990: 15s )

O nosso trabalho apresenta enfoques de percepção e de vivência urbana não pelos padres, arquitetos ou viajantes (a literatura dos viajantes é bastante rica), mas pelo romancista moderno, Dalcídio Jurandir (1909-1979), a fim de contribuir sobre a questão da fronteira entre cidade e campo e da vivência urbana e regional no ambiente dominado pela água e a floresta, a partir daquele que nasceu e viveu neste ambiente. Anteriormente, na literatura universal, a formação educacional e cultural configurou-se como tema principal do romance realista-naturalista também no Brasil e, também, pela obra de Herculano Inglês de Souza no Norte do Brasil. Desta forma, a tarefa da literatura era contribuir à questão da identidade humana, amazônica e brasileira - de um lado como projeto humano e, de outro lado, como projeto literário. Certamente, há uma coincidência entre o projeto nacional e o projeto de subjetivação e representação literária (Pré-Romantismo: Tempestade e Vontade; Iluminismo e Romantismo): a saída do homem da imaturidade (Kant).

E isso interessa em vista à situação histórica e política particular da Amazônia, refletida na obra de H.Inglês de Souza e nos romances de Dalcídio Jurandir como questão da formação educacional e humanista, no melhor sentido da palavra, ultrapassando o limite da questão da fronteira entre cidade e campo também na Amazônia.

Os dois projetos literários tratam a história de formação dos personagens principais, mas de forma diferente. Na obra de Inglês de Sousa apresenta-se a relação entre Brasil e Amazônia como processo entre "matutice e civilidade" (LEITE, 2002). Os pobres proprietários de terra na região amazônica, o pescador José e Miguel, o cacaulista do futuro, foram obrigados à formação e abandonaram-na. Enquanto Alfredo, personagem principal de D.Jurandir, insiste na formação escolar e humana, muda-se para Belém para estudar no colégio liceu. José e Miguel, Eutanázio (no primeiro romance de D.Jurandir, Chove nos campos de Cachoeira) e Alfredo não são habitantes dos centros, mas a experiência individual deles, como personagens, envolve "todo o árduo contar da própria coletividade" (F.JAMSON apud H.BHABHA,1998, p. 200). A sondagem existencial é mais do que uma introspecção de um determinado personagem; é a sondagem existencial de um grupo de seres humanos: os ribeirinhos do interior do Pará, o amazônida, os habitantes da Ilha de Marajó - mas no modo de apreensão artística de Dalcídio Jurandir, reconhece-se a ligação dialética entre o coletivo e o 
individual. O coletivo concretiza-se no indivíduo como indivíduo social e, com isso, depende do social, uma questão do poder econômico e político; o abandono do interior pelo dono do interior que vive na cidade grande, na metrópole.

Macunaíma, para referir o exemplo mais significativo na literatura brasileira, vindo da selva amazônica (Estado de Roraima), neste caso, tornou-se a bandeira da nacionalidade (herói brasileiro) em termos modernistas. A metrópole denomina o regional, mas traz o "regional" como exótico à metrópole; o regionalismo é uma expressão literária de outros "locais de cultura", mas o "herói sem caráter" torna-se emblemático para o debate dos anos 1920.

A nação era signo de modernidade "sob o qual diferenças culturais são harmonizadas na visão 'horizontal' da sociedade. A nação revela”, constata Homi Bhabha, “em sua representação ambivalente e vacilante, uma etnografia de sua própria afirmação de ser $a$ norma da contemporaneidade social"12. A norma se instala visando ao outro que não é ela, a nação, a metrópole. O personagem como sujeito é apreensível entre o "aqui” e "algum outro lugar", "na passagem entre contar/contado [...] e nessa cena dupla a própria condição do saber cultural é a alienação do sujeito" (BHABHA, 1998, p. 212). Então, a situação histórica e política na segunda década do século 20 mudou e a literatura regista e representa a nova vivência e experiência urbana e sua relação com o interior.

Sem escolaridade completa, Dalcídio Jurandir, o jovem de dezenove anos, filho de pai descendente de portugueses e de mãe descendente de escravos, tenta sua sorte como viajante clandestino para o Rio de Janeiro. Depois de um ano, ele volta ao Amazonas e consegue emprego como funcionário municipal em Gurupá/PA, onde escreve seu primeiro esboço de romance (1929). O emprego é de curta duração por causa das mudanças políticas implantadas pelo regime populista de Getúlio Vargas (1930-1945). Dalcídio vivencia o final da República Velha na beira do Rio Amazonas, depois volta para Belém e assumia, ativamente, a posição política da esquerda. Dalcídio reconhece, pelo próprio caminho escolar, a importância da escola e, neste caso, a da cidade. A fim de ver realizados os objetivos principais da democracia moderna ou da escola moderna, ele se engaje, na década de 1930, como inspetor escolar.

Maria dos Reis Campos ressalta o movimento escolar que se implanta no Brasil: "Nas escolas modernas [...] a biblioteca é parte integrante e da mais alta relevância no organismo escolar. Nas escolas mais modernas se vêem livros por toda parte, tendo-os os alunos com fartura à sua disposição, como acontece, por exemplo, nos Estados Unidos" (CAMPOS apud Diana G.VIDAL, In: ABREU, 2000: 335). “Ao ser introduzida no Brasil nos anos de 1920, a Escola Nova utilizara como estratégia discursiva distinguir-se do ensino em voga no país, denominando-o tradicional e qualificando-o de passivo, baseado unicamente na repetição de conteúdos memorizados" (VIDAL, "Livros por toda parte: o ensino ativo e a racionalização da leitura nos anos 1920-1930 no Brasil”. In: ABREU, 2000: 336). Enquanto Maria L.Tucci Carneiro frisa a contradição da sociedade moderna e burguesa: "Ser 
escritor, intelectual, tipógrafo, professor ou editor, entre 1924-1983, tornou-se perigoso, principalmente se o cidadão fizesse 'profissão de fé comunista'. E a situação poderia se complicar ainda mais se o suspeito, além de comunista, fosse membro da comunidade judaica, lituana, russa ou espanhola, radicada no Brasil” (Maria Luiza Tucci CARNEIRO, "Cultura Amordaçada: O DEOPS e o Saneamento Ideológico”. In: ABREU, 2000: 436). Dalcídio viveu concretamente esta situação. O único romance que tratou explicitamente uma questão política foi Linha do Parque (1959), que conta a história do movimento sindicalista e socialista no Extremo Sul, na primeira metade do século 20. Neste romance, Jurandir experimenta o estilo artístico-oficial do Realismo Socialista, pois atendeu o desejo do partido. Nos outros romances com o personagem central Alfredo, Dalcído configura a trajetória de um jovem do interior, na busca desta escolaridade que permite conhecer o mundo melhor.

Sob dificilíssimas condições econômicas e geográficas, Dalcídio encaminhou, em 1940, o manuscrito do primeiro romance Chove nos campos de Cachoeira que tinha esboçado, em Gurupá, em 1929, para o concurso literário da então importante revista Dom Casmurro (Rio de Janeiro). Totalmente desconhecido, ganhou o prêmio, e com o romance Marajó (escrito na década de 1930), que seus amigos tinham encaminhado, conseguiu ainda o terceiro lugar. Com a publicação do romance premiado, em 1941, Dalcídio mudou-se definitivamente para o Rio de Janeiro, onde passou a segunda metade da sua vida trabalhando como jornalista e realizando seu projeto literário. Ele conseguiu conquistar vários prêmios $^{13}$ e, em 1972, recebeu pela mão de Jorge Amado o prêmio Machado de Assis da Academia Brasileira de Letras pelo conjunto da obra.

A figura central Alfredo - um jovem inicialmente de mais ou menos doze anos, que vive na Ilha do Marajó, expressa o desejo ardente de se formar no e pelo mundo: "Mas Alfredo acorda com aquela cidade cheia de torres, chaminés, palácios, circos, rodas giratórias que lhe enchem o sonho e o carocinho. De olhos abertos para o telhado, pensa na sua ida para Belém. Seu grande sonho é ir para Belém, estudar" (Chove nos campos de Cachoeira, 1998: 188). Esse desejo é impulso e fio de Ariadne para mais oito romances: Três casas e um rio (1958), Belém do Grão Pará (1960), Passagem dos inocentes (1967), Primeira manhã (1967), Ponte do Galo (1971), Os habitantes (1976), Chão dos lobos (1976) e o último, Ribanceira (1978), em que o Alfredo tem vinte anos.

Os três romances iniciais têm o espaço do enredo os pequenos vilarejos da ilha; a paisagem do interior particular com seus campos alargados no tempo da chuva (inverno). Jean-Marc Besse que trabalha com a história e a epistemologia da geografia e com as questões de paisagem na cultura e na literatura afirma: "não há paisagem sem a coexistência do aqui e do além, coexistência do visível e do oculto, que define a abertura sensível e situada para o mundo". E continua, dizendo que a paisagem "não é uma categoria - e menos ainda uma experiência antropológica. Ela é pré-cultural, pré antropológica" (BESSE, 2006, p. 80). Podemos dizer que na "experiência paisagística" dos romances há duas direções: nos primeiros três romances, a Ilha de Marajó é vista na perspectiva da grande 
cidade Belém; a partir do quarto romance (Belém do Grão Pará), o interior é visto da perspectiva de Belém. No último romance (Ribanceira), pode-se entender um fechamento das duas perspectivas com a volta do personagem central ao interior. A experiência que na vida real do autor se duplicou, pois do interior foi para Belém e, depois, à capital política e cultural do país: Rio de Janeiro. "A paisagem é o espaço do sentir, ou seja, o foco original de todo o encontro com o mundo" (BESSE, 2006, p.80). No plano estético do projeto literário de Dalcídio, encontramos a densidade espiritual da situação políticocultural do país no início do século 20, posterior da Semana da Arte Moderna e da recondução da independência nacional tanto político e cultural quanto à situação do intelectual do Norte — da Amazônia. Desta forma, o projeto literário de Dalcidio é uma autêntica contribuição de um romance moderno que percebe e configura esteticamente aquilo que Besse conceitua como "paisagem humana". A paisagem, diz Besse, está ligada "à existência de um horizonte" (BESSE, 2006, p. 79). O horizonte concreto, o além da paisagem da ilha e da cidade de Belém, é cultural no sentido mais amplo. "Toda vontade de conhecer a paisagem e todo esforço para habitá-la de modo refletido estão essencialmente ausente delas. Como se ao houvesse paisagem possível senão no exílio" (BESSE, 2006, p. 81s). Dalcídio Jurandir escreveu a maior parte dos romances no "exílio" típico do escritor paraense e amazonense, no século 20 (J.Veríssimo, H.Inglês de Souza, Abguar Bastos, Tiago de Mello e, mais tarde, Milton Hatoum), no Rio de Janeiro, capital política e cultural do Brasil ou em São Paulo, capital econômica e moderna. E Dalcídio estava ligado, politicamente e como romancista ao Brasil, à Weltliteratur, a literatura do mundo, uma mudança era extremamente necessária. Escrevendo sobre "sua gente", ele escreveu como escritor brasileiro, longe da sua terra. "A paisagem é essencialmente mais mundo do que natureza, ela é mundo humano, a cultura como encontro da liberdade humana com o lugar do seu desenvolvimento: a Terra" (BESSE, 2006, p. 92).

No século 20, o mundo idealizado é substituído pelo mundo melancólico da utopia ou pelo mundo kafkiano. Identidades procuradas através da literatura não são mais ideais, são utopias melancólicas ou representações da mímesis dos romances do século 19. Dalcídio Jurandir compreende sua obra no contexto do romance moderno e se refere a três grandes "políticos no romance moderno sob a aparência de artistas puros ou puros visionários: Kafka, Joyce, Faulkner” (D.JURANDIR, 1996: 33). E pensando na visibilidade duradoura do escritor, a visibilidade poética, o próprio escritor confirma: "Já é uma banalidade dizer que é impossível a um romanista, o menos intemporal dos artistas, fugir do seu tempo. E intemporal, uma palavra, ela existe? Atrás dela pode estar o paraíso, ou a evasão mais sem vergonha. O que existe é o homem, terrestre, temporal como o diabo, e está aí a sua grandeza" (D.JURANDIR, 1996: 33). 
O grande desejo, do século 19, se configurou como projeto moderno, projeto de formação, de educação, de conquistar o mundo pela razão, se despede diante do declínio da Modernidade, da grande frustração diante da experiência urbana das grandes cidades, no início do século 20. O "projeto" de Modernidade fracassou. Ilusório seria acreditar que o projeto somente não se completou, como pensa Jürgen Habermas. A proposta de "auto-aperfeiçoamento", no projeto burguês do século 19, recuo para o nível da percepção e da análise refletiva, diante do mundo moderno.

Alfredo, voltamos para o romance de Dalcídio, finalmente e com todo o apoio da mãe ("Sua mãe continuando a pilar o alho, exclamou:/ — Meu filho, tu vais, sim, pro colégio [...] Meu filho, nós vamos embora [...] Meu filho, te levo pra cidade“; D.Jurandir, Tres Casas e um rio, 1994: 214s) consegue mudar para Belém e iniciar a desejada realização dos seus estudos. Mas, encontrando-se no meio de mundo em contradições políticas e culturais, percebe um mundo em decadência; os valores humanistas e dos primeiros burgueses estão em ruínas como a nova moradia da família Alcântara. O livro abre de forma clássica do romance do início do século 19, como romance histórico: a história da cidade como capítulo político da Amazônia, mas também com a história familiar. Só esta família não está em ascensão, em que Alfredo se hospede, trata-se de uma família da classe média em declínio, analogamente ao declínio da região amazônica depois da época da borracha.

Com a queda do velho Lemos, no Pará, os Alcântaras se mudaram da 22 de Junho para
uma das três casas iguais, a do meio, de porta e de duas janelas, n. 160, na Gentil
Bittencourt. Era o trecho em que passava o trem, atrás do quartel do 26 de Caçadores. O
toque de alvorada acordava o seu Virgílio para a Alfândega [...] Longe estavam da sorte
dos Rezendes, lemistas de cabo a cabo, hoje coitados se acabando numa palhoça dos
Covões [...] - Que serra de Guaramiranga, que montanha de Minas, Suíça coisa
nenhuma! Basta o ar desta baixa, o origã do lixo e da lama ai dos fundos [...] Que mais
desejam, seus Alcântaras, depois desta Avenida Gentil Bittencourt, cento e sessenta?
Avenida! Avenida!” (D.Jurandir, Belém do Grão Pará, 1960: 5)

"Auto-conhecimento", como diz Pedro Maligo ${ }^{14}$ é um termo chave que se encontra deste o primeiro romance de Dalcídio, "uma necessidade íntima que deve ser satisfeita ao tempo em que se lida com a realidade externa que impõe as dificuldades materiais a serem vencidas" (MALIGO, 1998, p. 54). Pois bem, no mundo de Dalcídio Jurandir, essas dificuldades não são mais superáveis. A compreensão melancólica do mundo tematiza de forma diferente a luta social; o "cenário simbólico" é substituído pelo cenário alegórico. Estamos no mundo da dissolução ética e moral, da desorientação total, da indeterminação - mas o personagem acredita na utopia, mesmo que o discurso narrativo distanciado alimenta a dúvida no leitor, pois o autor (responsável pelo discurso narrativo) já sabe que a utopia não se realizará - é isso que o deixa melancólico, mas não sem resposta. O mundo da vivência como experiência (o clássico Guilherme Mestre no mundo do teatro), nos primeiros romances, é o mundo da cultura livresca ainda no interior: "A fonte de informação é apresentada quanto o fora da 
literatura naturalista: é uma cultura livresca, estrangeira, que oferece a Alfredo os meios para interpretar a realidade, com a diferença de que a fonte em si - a coleção de dicionários do seu pai - é caracterizada como o mais exótico objeto que Alfredo conhece, uma vez que lhe apresenta inalcançáveis relevos estrangeiros" (MALIGO, 1998, p. 56). Nos romances urbanos a partir de Belém do Grão Pará, Alfredo passa várias vezes as férias no interior, confrontando-se com os seus próprios sonhos da infância.

\begin{abstract}
Riscará esta palavra. 'Mande [...] o Dicionário de Latim, mas mande escondido do papai, é possível?'

Não. Fazia dó furtar o Dicionário. Não ia apenas deixar um vazio no estante mas também no pai. No chalé, o Dicionário era que nem uma pessoa, embora mitológica. Nunca via o pai abrilo, sempre no seu lugar, com a sua língua de missa e botânica. Uma semana antes da volta a Belém, de noite, no chalé, sonhando com o Ginásio, embalava-se na rede, roçando o pé na estante envidraçada que se abriu. O pé tocava na lombada do Dicionário. Era tocar e irrompiam do livro aquelas vozes mortas que tantos séculos falaram a língua ali sepultada. Pôs-se a escutar o imenso coro, o numeroso latim dos oradores e das legiões, das orgias e dos templos, das césares e dos santos... Sobre aqueles séculos do falar latim, embalava-se, embalava-se, o pé na tumba sonora. Parou o embalo, fechou o estante, desceu ao campo e tentou descobrir onde a matinta-perera tanto agourava"
\end{abstract}

(D.Jurandir, Primeira manhã: 1967: 2)

Podemos dizer que o romance Belém do Grão Pará (1960) marca a mudança da perspectiva deste ponto de vista. Enquanto a experiência com e da cidade ainda é uma "experiência física" do declínio social da família dos Alcântaras, os próximos romances descrevem cada vez mais as experiências psicológicas e de formação vivenciadas diante das contradições sociais.

No quinto romance, Passagem dos inocentes (1967), Alfredo mora ainda no contorno próximo do centro, mas a passagem da nova moradia com o nome inglês "Mac Donald" é cheio de lama. A escola continua e ele consegue passar para o ginásio. Os anos em seguida marcam mais mudanças de moradia, que o levam cada vez mais à periferia da grande cidade. As experiências urbanas e sociais, sempre reencontrando a família, os parentes e amigos da infância durante as férias marcam o adolescente. Na cidade, Alfredo é o menino pobre do interior e, na ilha, ele é o rapaz da cidade: "E a [Dadá] escutava, como se ela lhe dissesse: que tu chegues da cidade, de sabedoria coberto, me altera? Queres que eu descubra a cabeça, saber que o meu cabelo caiu? Queres cerrar de cima? Grandes coisas, chegares da cidade [...] A cidade de que vens te emproando? [...] Que tenho eu com o teu estudo?” (D.JURANDIR, 1971, p. 9s). Frequentar o ginásio torna-se martírio, pois tem muita dificuldade adquirir uma roupa adequada (por exemplo, o uniforme escolar); particularmente, as contradições sociais o incomodam dramaticamente, ante do conhecimento transmitido na escola e as suas experiências urbanas.

O Ginásio.

Que fazia no Ginásio senão acelerar este enjôo das aulas e dos mestres? Nunca adivinham? Latim? O Dr. Menezes empunhava a bengala e as declinações contra os roceiros do Guamá ${ }^{15}$. 
A vivência e a experiência urbanas se expressam na forma fragmentada e desigual dos capítulos e no estilo de narrar descontínuo e digressivo. Nisso, reside a força da prosa de Dalcídio Jurandir. E, como forma de resistência, seu herói Alfredo não cresce; Alfredo pensa: "E eu que vim da cidade, lá estudo, via as coisas... As meninas não eram mais. Só eu não crescia conforme?” E o narrador completa umas paginas depois: "Nhá Lucíola, sempre na sua sombra, a invisível mão a toca-lo, a dizer-lhe numa voz ausente: não te quero crescido" (D.JURANDIR, 1984, p. 19 e 24). O nãocrescimento de Alfredo pode ser entendido como estratégia literária de retardar o futuro diante da incerteza do futuro.

Os romances perpassam mais ou menos dez anos de vida de Alfredo (de 10 a 20). O herói do Romance de Formação do século 19 começa suas "aventuras" com mais ou menos 20 anos. O personagem central, Alfredo já começava cansado demais. Ele é todo pensativo. "Voltou muito cansado. Os campos o levaram para longe. O caroço de tucumã também” (D. JURANDIR, 1998: 117). O objeto mágico de contar histórias, o caroço de tucumã, se perdendo nos campos, é recuperável, mas na cidade o caroço perde toda a função - o mundo desencantado da grande cidade é prosaico e não poético. O final do romance Belém do Grão Pará - os Alcântaras devem sair urgentemente da casa alugada que começa desmoronar - desencanta mesmo e toda cultura burguesa da vida urbana simbolizada no instrumento clássico da Hausmusik, concerto doméstico.

Fez ver: tinham que mudar aquela hora mesma. Para onde, não sabia, mas tinham. Pelo menos retirar a bagagem para a calçada, não no quintal [...] E o piano? Já no quintal, ao pé do cacto, d.Inácia apagava-se nas sombras. Libânia [a criada] correu até ao Largo da Pólvora em busca dos portugueses [...] encontrou um, que convocou os demais e carregaram o piano até a porta. Aí, perguntaram: "aqui na calçada ou no leiloeiro?" Libânia franziu a testa, indica-lhes ao pé da mangueira o lugar do piano.

(Belém do Grão Pará, 2005: 524).

\section{Referências}

Abreu, Márcia (Org.). Leitura, História e História da Leitura. Campinas: Mercado de Letras 2000.

Azevedo, José E. de. Literatura Paraense. Belém: FCPTV/SECULT 1990.

Besse, Jean-Marc. Ver a Terra. Trad. Vladimir Bartalini. São Paulo: Perspectiva 2006.

Bhabha, Homi. O Local da Cultura. Trad. Myriam Avila et alii. Belo Horizonte: EDUFMG 1998.

César, Guilhermino (Org). Historiadores e Críticos do Romantismo. São Paulo: EDUSP 1978.

Dutra, Eliana R. de Freitas. "O Almanaque Garnier, 1903-1914: ensinando a ler o Brasil, ensinando o Brasil a ler”. In: Abreu, 2000: 477-504. 
Fernandes, Lílian. "História da Difícil Conquista do Acre”. In: O Liberal (Belém), 31/12/2006, p. 7 ("Revista da TV").

Geertz, Clifford. O Saber Local. Novos Ensaios em Antropologia Interpretativa. Trad. Vera Mello Joscelyne. Petrópolis/RJ: Vozes 2006 ( $8^{a}$ ed., primeira edição 1997; original de 1983).

Jurandir, Dalcídio. "Um Escritor no Purgatório" (Interview mit Antonio Torres, Haroldo Maranhão und Pedro Galvão). In: Asas da Palavra (Belém) Nr. 4/1996: 28-30 (original 1976).

— Chove nos Campos de Cachoeira. Belém: UNAMA 1998 (6 $6^{\mathrm{a}}$ ed.).

— Três Casas e um Rio. Belém: CEJUP 1994 (2 $2^{\mathrm{a}}$ ed.).

— Belém do Grão Pará. Belém/Rio de Janeiro: EDUFPA/FCRB 2005 (4ª ed.).

_ Passagens dos Inocentes. Belém: Falangola: 1984 (2ª ed.).

— Primeira Manhã . São Paulo: Martins 1967.

— Ponte do Galo. São Paulo/Rio de Janeiro: Martins/NLE 1971.

— Ribanceira. Rio de Janeiro: Record 1978.

Leite, Marcus V.C. A Dialética da Matutice e da Civilidade. Belém: Monografia de Especialização no NAEA 1996 e Cenas da Vida Amazônica. Belém: UNAMA 2002.

Linhares, Temístocles. História Crítica do Romance Brasileiro (1728-1981). Vol. II. Belo Horizonte: Itaitiaia; São Paulo: EDUSP 1987 (Coleção Reconquista do Brasil, 2a . Série, vol. 117).

Maligo, Pedro. Land of Metaphorical Desires. The Representation of Amazonia in Brazilian Literature. New York/Washington/DC: Peter Lang 1998 (Wor(l)ds of Change. Latin American and Iberian Literature, 21).

Meira, Clóvis/Ildone, José/Castro, Acyr. Introdução à Literatura no Pará. Belém: CEJUP 2a ed. 1990.

Nery, Frederic José de Santa-Anna. Folc-Lore Brésilien. Paris: Perrin 1889; ed. bras. Folclore Brasileiro. Recife: Fundação Joaquim Nabuco/Massangana 1992.

Nunes, Benedito/Hatoum, Milton. Crônica de Duas Cidades: Belém e Manaus. Belém: SECULT: 2006.

Rocque, Carlos (Org.), Grande Enciclopédia da Amazônia. Antologia da Cultura Amazônica. Vol. I. Belém: Amada 1970.

Rother, Larry. "Língua Nascida do Colonialismo prospera novamente na Amazônia”. In: Somanlu (Manaus), no. 2/2005: 231-234. Trad. Georg El Khauti Andolfato (publicado na New York Times e na Folha on-line, em 28/08/2005).

Salles, Vicente. “Classificação Decimal do Folclore”. In: Américo Pellegrini Filho (org.), Antologia de Folclore Brasileiro. São Paulo: EDART/Belém: UFPA/João Pessoa: UFPB 1992. 
Santa-Anna Nery, José de. Folc-Lore Brésilien. Paris: Perrin 1889; ed. bras. Folclore Brasileiro. Recife: Fundação Joaquim Nabuco/Massangana 1992.

Schapochnik, Nelson. "Das ficções do arquivo: ordem dos livros e práticas de leitura na Biblioteca Pública e Nacional do Rio de Janeiro". In: Abreu, 2000: 273-311.

Vidal, Diana Gonçales. "Livros por toda parte: o ensino ativo e a racionalização da leitura nos anos 1920-1930 no Brasil". In: Abreu, 2000: 235-255.

Villalta, Luiz Carlos. "Os leitores e os usos dos livros na América Portuguesa". In: Abreu, 2000: 183-212.

Zilberman, Regina. “O Positivismo e a História da Literatura Brasileira”. In: M.E.Moreira (Org.), Histórias da Literatura: Teorias, Temas e Autores. Porto Alegre: Mercado Aberto 2003.

${ }^{i}$ Doutor. Professor do PPGLSA. Pesquisador do CNPq. grupe @ufpa.br

${ }^{2}$ Cf. Luiz Carlos Villalta, que compara as bibliotecas na América Portuguesa, ressalta: "A modéstia das bibliotecas familiares e individuais do período encontrava o contraponto nos colégios jesuíticos: um inventário feito sobre os livros da biblioteca do colégio da Bahia, em 1694, registra a quantia de 3.000 volumes, no Rio de Janeiro, no início do século XVIII, no espaço da biblioteca, estima-se, poderiam caber 5.000 livros; no Pará, em 1718, um total de 1.263 volumes" (2000: 187). E um pouco mais adiante, Villalta apresenta um quadro sociológico, levantado em Mariana/Minas Gerais, entre 1714 e 1822, "de todos os inventários de leigos e clérigos existentes no cartório" (2000: 191). "Dentre os inventariados (911), os proprietários de biblioteca eram $76(8,34 \%)$ [...] 71 eram brancos e livres, 1 era mulato e livre, 1 era negro e forro, e os 3 restantes não tinham cor e condições especificadas. As mulheres somavam 9 $(11,84 \%)$, enquanto os homens chegavam a $77(89,15 \%)$ " (2000: 192). Isso mudou com a chegada da corte de D.João VI: "Quando se visita o Rio de Janeiro não se deve deixar de ir à Biblioteca Nacional. Foi ela organizada com os livros procedentes da Biblioteca Real de Portugal [...] Todavia o número de livros tem aumentado devido a valiosas contribuições, entre as quais merecem destaque as coleções do finado José Bonifácio de Andrada" (Kidder apud Schapochnik, 2000: 278). Berenice Cavalcante esclarece: "vale registrar que sua [José Bonifácio] bagagem, ao desembarcar no seu 'Novo Portugal' [depois de 40 anos na Europa] incluía uma biblioteca de dimensão considerável para os padrões da época: mais de 6.000 livros" (In: Abreu, 2000: 235). Só um dado a mais sobre a quantidade de leitores, a Biblioteca Pública no Rio de Janeiro, em 1875 (275.000 habitantes), "acolheu um total de "6.425 leitores, que consultaram 6.923 obras"” (Schapochnik, In: Abreu, 2000: 292). A presença de jornais e revista "no topo da listagem das obras mais requisitadas", frisa o estudioso, "permite pensar na heterogeneidade desses leitores e nas diferentes possibilidades de uso desses impressos na medida em que eram oferecidas informações sobre $o$ debate parlamentar, o movimento dos portos e leilões de mercadorias, folhetins, avisos vários (sobre a fuga de escravos, anúncios de livros e produtos farmacêuticos, prestadores de serviço)" (Schapochnik, In: Abreu, 2000: 309).

3 “'A tipografia - não há quem a ignore - estabeleceu-se no Brasil muito tarde, no momento da trasladação da Corte portuguesa para o Rio de Janeiro" (G.César, 1978: XXIX).

${ }^{4}$ No Rio de Janeiro fundam-se as livrarias européias Laemmert (1828) e Garnier (1844). A primeira livraria brasileira instalou-se no Rio de Janeiro, em 1883, quando o português naturalizado Francisco Alves assumia a empresa do tio (Aníbal Bragança, 2000: 452s). O famoso Almanaque Garnier relaciona, no início do século 20, "os pontos onde ele cultiva leitores e clientes, para além do Rio de Janeiro: Maranhão sim, Pará não (Eliana R. de Freitas Dutra, "O Almanaque Garnier, 1903-1914: ensinando a ler o Brasil, ensinando o Brasil a ler". In: Abreu, 2000: 489).

${ }^{5}$ No início do século 20, consta um índice de analfabetismo na faixa de 90\% (E.Dutra, In: Abreu, 2000: 477). Também se registra um fato curioso sobre a questão da língua: Larry Rother, "Língua Nascida do Colonialismo prospera novamente na Amazônia", 2005: 231-234.

${ }^{6}$ O termo "folklore" é central no estudo de Frederic José de Santa-Anna Nery (1992 [1889]). O subtítulo reúne: "Poesia Popular, Contos e Lendas, Fábulas e Mitos, Poesia, Música, Danças e Crenças dos Índios. Acompanhado de doze peças de Música". A apresentação de Vicente Salles, que também assina pela tradução, cronologia e notas adicionais, esclarece: "Até o final do século XIX, os estudos de Folclore no Brasil obedeciam à orientação etnográfica. Sílvio Romero, crítico literário, ainda trabalhou como etnógrafo. $\mathrm{O}$ uso do termo folclorista, para indicar os que se dedicavam a esses estudos, já vigorava no seu tempo e alguns pesquisadores são tal designados" (1992: 11). O paraense Barão Santa-Anna Nery, "representante típico do velho regime [...] apresenta em língua francesa um mosaico do folclore 
brasileiro" (1992: 11) e alcança uma grande repercussão na Europa, mas ficou quase desconhecido no Brasil. A tradução só se realiza com a edição de 1992, mais de 100 anos depois.

${ }^{7}$ Vicente Salles apresenta uma estatística da população para o ano de 1798: 45,2 \% de brancos e 45,9 de escravos, "que somados a índios, negros e mestiços libertos, elevava-se para 54,8\%" (C.Meira, 1990: 49). Salles ressalta a significação da oralidade, constata Meira: "Com a expulsão dos jesuítas [...] a mudança na denominação indígena das aldeias e vilas para nomes portugueses, certamente que terão influído para a lentidão desse desenvolvimento cultural. A igreja, os religiosos, jesuítas ou não, tomaram papel saliente nessa modelagem da cultura, desde os tempos de Bettendorf e Vieira. A memória oral transmitindo às gerações que surgiam os usos, costumes, crenças, muitas delas passando a ser incorporadas à cultura e ao desenvolvimento da língua portuguesa" (1990: 50).

${ }^{8}$ C.Meira/J.Ildone/A.Castro, 1990: 72 e cf. também os capítulos sobre o início do século 20, de J.Ildone, pp. 173 -205. Rio de Janeiro consta com 149 tipografias, no período de 1808 a 1900, 30 livrarias, em 1870, e 45, em 1900 (Tania M.T.Bessone da Cruz Ferreira, In: Abreu, 2000: 314).

${ }^{9}$ C.Rocque, 1970: 31. Cf. os capítulos 8 e 9. Livros de Raimundo de Farias Brito (1862-1917) constam no programa da editora do Senado Federal (Brasília) e o professor-educador continua na memória literária: "Recordava Farias Brito, o filósofo, que frequentava a casa, na Vinte e Dois, ao tempo do lemismo. Molhava no prato de tucupi ou na sopa de tartaruga as mangas do fraque a dizer: 'comei, bebei, minhas mangas, que as homenagens são todas para vós e não a quem vos vestiu"' (D.Jurandir, 2004: 47s).

${ }^{10}$ B.Nunes, 2006: 38. A última frase de Nunes indica algo acontecido que afastou o aparente progressista Veríssimo de Belém e dos paraenses, o que reclama depois J.E.de Azevedo (mais adiante). Cf. R.Zilberman, "O Positivismo e a História da Literatura Brasileira". In: M.E.Moreira, 2003: 115-156.

${ }_{11}$ J.E. de Azevedo, Literatura Paraense, 1990: 25. Com toda razão, por exemplo, respondendo às perguntas do Almanaque Brasileiro Garnier sobre leitura e livros, J.Veríssimo relaciona autores "como Alvarenga, Gonzaga, Gonçalves Dias, Varela, Casimiro de Abreu, Álvares de Azevedo, Castro Alves [...] os romances de Macedo, Alencar, Bernardo Guimarães" (E.Dutra, In: Abreu, 2000: 494) - nem pensar em H.Inglês de Sousa.

${ }^{12}$ Bhabha 1998: 212. Cf. Clifford Geertz, O Saber Local. Novos Ensaios em Antropologia Interpretativa, 2006. Neste contexto, cabe como comprovação empírica da dicotomia contínua o depoimento de Marcos Schechtman, diretor das gravações na Amazônia da minisérie da TV GLOBO, Amazônia - De Galvez a Chico Mendes (2006/2007): "Gravamos o máximo que podíamos lá, para ter o cheiro e o sabor locais. A viagem foi fundamental para entendermos a Amazônia, que tem um outro código, é outro universo cultural" (Lílian Fernandes, "História da Difícil Conquista do Acre", 2006, p. 7).

${ }^{13}$ O prêmio Paula Brito, da Biblioteca do Estado da Guanabara, pelo romance Belém do Grão Pará, o prêmio Luíza Cláudio de Souza, criado pelo Pen-Club do Brasil, em 1960. A fim de ilustrar a importância dos prêmios citados, seguem nomes de outros vencedores daquele tempo: Jorge Amado (Prêmio Paula Brito, Prêmio Luíza Cláudio de Souza, e o Prêmio Machado de Assis, em 1959); João Guimarães Rosa (Prêmio Paula Brito, em 1956 e o Prêmio Machado de Assis, em 1961), Josué Montello Jr. (Prêmio Paula Brito, em 1959) e Álvaro Lins (Prêmio Luíza Cláudio de Souza pelas obras Os Mortos de Sobrecasaca e Jornal de Crítica - Sétima série, em 1963).

${ }^{14}$ Maligo, Pedro. Land of Metaphorical Desires. The Representation of Amazonia in Brazilian Literature. 1998: 54: "ao passo que no texto pós-modernista a aventura da vida aparece sob a forma do autoconhecimento".

${ }^{15}$ Ponte do Galo, 1971: 28. O Guamá é um bairro afastado do centro de Belém, na margem do rio de mesmo nome. Hoje, encontra-se lá a Universidade Federal do Pará. 